\title{
Ensuring contraceptive security through effective supply chains
}

Moazzam Ali

Follow this and additional works at: https://knowledgecommons.popcouncil.org/departments_sbsr-rh

Part of the Demography, Population, and Ecology Commons, Family, Life Course, and Society Commons, International Public Health Commons, Operations and Supply Chain Management Commons, and the Women's Health Commons How does access to this work benefit you? Let us know!

\section{Recommended Citation}

Ali, Moazzam. 2017. "Ensuring contraceptive security through effective supply chains," Family Planning Evidence Brief. Geneva: World Health Organization. 


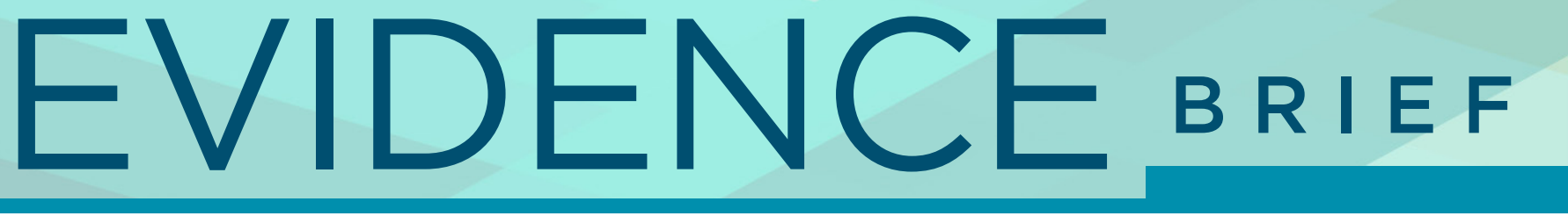

\section{Ensuring contraceptive security through effective supply chains}

\section{$\rightarrow$ Strengthening supply chains to meet the growing demand for family planning will require systems diagnostics, supply chain redesign or adjustments, strategically located storage and distribution systems, adequate staffing and training, and better information about inventory and financing.}

Establishing and maintaining well-functioning supply chains that meet the needs of public and private sectors, as well as health professionals at all levels in family planning (FP) programmes, will play a critical role in reducing unmet need for modern contraception in low and middle income countries (LMICs). Supply chain management comprises the steps involved in moving a product from the supplier to the customer (1). Lack of access and supply chain failures are principal reasons cited by women in LMICs for non-use of contraceptives and contraceptive discontinuation $(2,3,4)$

Efficient supply chains improve quality of care and support women's choice of modern contraceptive methods by reducing stock-outs of supplies and medical equipment (5). Insufficiencies in supply chains are attributable to a variety of causes, including low client demand and lack of trained staff. The number of countries in which at least 85 percent of primary service delivery points offered three or more methods increased from 7 in 2013 to 20 in 2015(6).

\section{BARRIERS AND CHALLENGES}

Several factors contribute to weak supply chains in LMICs, especially in rural and peripheral areas where clients are hard to reach. Barriers include:

- Weak logistics management information systems and inadequate information about inventory, financing, and product flows to guide procurement $(7,8,9,10)$.

- Inadequate infrastructure, including insufficient road networks and lack of appropriate storage facilities $(8,9,10,11)$.

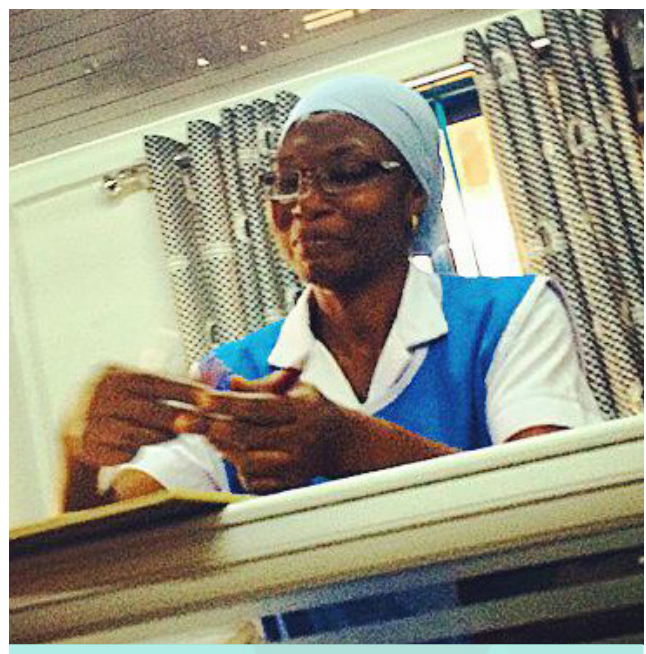

\section{POLICY AND PROGRAM CONSIDERATIONS}

To establish and maintain wellfunctioning supply chains for contraceptives:

$\rightarrow$ Improve logistics information for inventory management; use mobile technology to improve reporting between supply chain levels; and consider different supply chain models designed to address inefficient operations.

$\rightarrow$ Leverage the expertise of the private and public sector to ensure a total market approach to supply chain management.

$\rightarrow$ Strengthen the capacity of public and private sector family planning providers and managers and create opportunities for their closer collaboration. 
- Absence of a stable, well-trained human resource base dedicated to supply chain management $(8,9,11,12,13)$.

- Inadequate domestic and international funding for the procurement of commodities $(7,9,10)$.

Strengthening supply chains to meet the growing demand for FP will require systems diagnostics, supply chain redesign or adjustments, strategically located storage and distribution systems, adequate staffing and training, and better information about inventory and financing. An effective and efficient supply chain helps women meet their reproductive intentions (14).

Effective supply chains also have the potential to create and meet latent demand for methods that were previously unavailable, as exemplified by Senegal's use of the informed push model (IPM), where sharp increases of 11 percentage points were recorded in one year in the Dakar region due to the reliable availability of commodities (9).

\section{CONSIDERATIONS FOR ENSURING CONTRACEPTIVE SECURITY THROUGH EFFECTIVE SUPPLY CHAINS}

Two evidence-based solutions address the challenges described above:

- Increase the visibility of product flows and user demand. Improve logistics information for inventory management; use mobile technology to improve reporting between supply chain levels (15); consider different supply chain models designed to address inefficient operations; and reevaluate pull-based systems if they are ineffective (9).

- Leverage the expertise of the private and public sector to ensure a total market approach to supply chain management. Strengthen the capacity of public and private sector FP providers and managers and create opportunities for their closer collaboration $(8,11,12,13,16,17,18)$.

In the context of supply chain optimization, the following solutions have been enacted in innovative ways:

- Implementation of national collaborative platforms or VANs (Visibility and Analytics Networks) of people, processes, and technology that capture and use supply chain data from multiple sources to improve decision making (6).

- Creation of a "Global Visibility and Analytics Network" (Global VAN) that streamlines access to in-country data and reduces parallel data flows, while also capturing data from manufacturers, procurers, freight forwarders, and others in the supply chain. The Global VAN facilitates data harmonization and provides a single platform for obtaining the data needed to ensure the supply of products to country programmes (19). Adoption of common data standards and "trace and tracking" options for health commodities will facilitate global metrics $(20,21)$.
- Adoption of the informed push model of contraceptive distribution in Senegal and Togo has resulted in greater operational efficiencies and the potential for increased quantities of supplies to drive demand and use $(9,22)$.

- Commitment by the governments of Ethiopia, Malawi, and Rwanda to strengthening supply chains for modern contraceptives has demonstrated that the greatest benefits are realized when product flow, data flow, and effective people are in place and working together (8).

- $\quad$ Strengthening supply chains involves policy and programmatic activities such as integration and decentralization. The government of Chile uses framework contracts to pool procurement of essential medicines in a decentralized health system. These contracts save the Chilean government nearly US $\$ 8,000$ per procurement in management costs and create a more agile supply chain (23).

- Integration of family planning services into other health services is promising and often leads to merging of programmatically separate (or vertical) supply chains as part of broad health sector reforms. The Ministry of Health in Mongolia through a longterm strategic partnership agreement with the private sector is dealing with all health commodities and regulating the service charges. This strategic action is a useful step towards strengthening public and private partnerships in the health sector and improving the national health supply chain (5).

- $\quad$ Finally, to be effective and efficient, supply chain interventions must have political commitment from national governments; active involvement of all stakeholders; adequate financial and manpower resources; appropriate quality and quantity of supplies; and effective logistics management, including forecasting, inventory control, distribution, and data.

\section{REFERENCES}

1 Jacoby D. Guide to supply chain management: how getting it right boosts corporate performance. John Wiley \& Sons; 2009.

2 Alkema L, Kantorova V, Menozzi C, Biddlecom A. National, regional, and global rates and trends in contraceptive prevalence and unmet need for family planning between 1990 and 2015: a systematic and comprehensive analysis. Lancet. 2013;381(9878):1642-52.

3 Bradley J, Mursagulova N, Nosa M, Searing H. Supply and demand challenges to modern contraceptive use in Azerbaijan. Eur J Contracept Reprod Health Care. 2007;12(2):175-83.

4 Sedgh G, Hussain R. Reasons for contraceptive nonuse among women having unmet need for contraception in developing countries. Stud Fam Plann. 2014;45(2):151-69.

5 High Impact Practices in Family Planning (HIP). Supply chain management: investing in contraceptive security and strengthening health systems. Washington, DC: USAID; 2012 Nov. Available from: http://www. fphighimpactpractices.org/resources/supply-chain- 
management-investing-contraceptivesecurity-andstrengthening-health-systems (Accessed on June 20, 2017).

6 UNFPA supplies. Annual report 2015. https://drive.google. com/file/d/OB9D17AOk5PiRclAtTIZWUnR4SmM/view

7 Chandani $Y$, Breton G. Contraceptive security, information flow, and local adaptations: family planning Morocco. Afr Health Sci. 2001;1(2):73-82.

8 Chandani Y, Andersson S, Heaton A, Noel M, Shieshia M, Mwirotsi A, et al. Making products available among community health workers: Evidence for improving community health supply chains from Ethiopia, Malawi, and Rwanda. J Glob Health. 2014;4(2):020405.

9 Daff BM, Seck C, Belkhayat H, Sutton P. Informed push distribution of contraceptives in Senegal reduces stockouts and improves quality of family planning services. Glob Health Sci Pract. 2014;2(2):245-52

10 Vledder M, Friedman J, Sjöblom M, Brown T, Yadav P. Optimal supply chain structure for distributing essential drugs in low income countries: Results from a randomized experiment. Ross School of Business Paper. 2015;1269.

11 Shieshia M, Noel M, Andersson S, Felling B, Alva S, Agarwal $S$, et al. Strengthening community health supply chain performance through an integrated approach: Using mHealth technology and multilevel teams in Malawi. J Glob Health. 2014;4(2):020406.

12 Prata N, Gessessew A, Cartwright A, Fraser A. Provision of injectable contraceptives in Ethiopia through communitybased reproductive health agents. Bull World Health Organ. 2011;89(8):556-64.

13 Lebetkin E, Orr T, Dzasi K, Keyes E, Shelus V, Mensah S, et al. Injectable contraceptive sales at licensed chemical seller shops in Ghana: access and reported use in rural and periurban communities. Int Perspect Sex Reprod Health. 2014;40(1):21-7.

14 EngenderHealth. 2011. The SEED Assessment Guide for Family Planning Programming. New York.

15 J. Barrington, O. Wereko-Brobby, P. Ward, W. Mwafongo, S. Kungulwe. SMS for Life: a pilot project to improve antimalarial drug supply management in rural Tanzania using standard technology. Malar J, 9 (1) (2010), p. 298 http:// dx.doi.org/10.1186/1475-2875-9-298

16 Akol A, Chin-Quee D, Wamala-Mucheri P, Namwebya JH, Mercer SJ, Stanback J. Getting closer to people: family planning provision by drug shops in Uganda. Glob Health Sci Pract. 2014;2(4):472-81.

17 Prata N, Weidert K, Fraser A, Gessessew A. Meeting rural demand: a case for combining communitybased distribution and social marketing of injectable contraceptives in Tigray, Ethiopia. PLoS One. 2013;8(7):e68794.

18 Stanback J, Mbonye AK, Bekiita M. Contraceptive injections by community health workers in Uganda: a nonrandomized community trial. Bull World Health Organ. 2007;85(10):768-73.

19 Reproductive Health Supplies Coalition. https://www. rhsupplies.org/fileadmin/uploads/rhsc/Newsletters/ Supplylnsider/2016-12-Supply-Insider-English.pdf (Accessed on June 20, 2017)
20 Reproductive Health Supplies Coalition. https://www. rhsupplies.org/fileadmin/uploads/rhsc/General_ Membership_Meetings/Mexico_2014/Presentations/Day_1/ SSWG_-_Panel_1_-_iSCM_D4M_-_Campbell_Bright_-_ UNFPA.pdf (Accessed on June 20, 2017)

21 USAID. Deliver Project. Final country report. Ethiopia. 2016. http://deliver.jsi.com/wp-content/uploads/2017/01/ FinaCounRepo_ET.pdf (Accessed on June 20, 2017)

22 Reproductive Health Supplies Coalition. https://www. rhsupplies.org/fileadmin/uploads/rhsc/General_ Membership_Meetings/Mexico_2014/Presentations/ Day_4/PS_Availability_-_High_Impact_SCM_Practices_-Renee_van_der_Weerdt_UNFPA.pdf (Accessed on June 20, 2017)

23 Goya F. Balance y Perspectivas de los convenios marco. Presented at the VI Annual Conference on Government Procurement in the Americas; Lima, Peru; October 2010.

Author: Moazzam Ali, World Health Organization. Support provided by Madeline Farron.

This is one of seven Family Planning Evidence Briefs prepared for the Family Planning Summit held in London on July 11, 2017. The briefs highlight evidence and provide research and programme considerations for improving access to family planning and reducing unintended pregnancy. Programme considerations are based on the expert views of the authors, who undertook desk reviews drawing on existing evidence.

\section{Family Planning Evidence Briefs}

- Accelerating uptake of voluntary, rights-based family planning in developing countries (overview)

- Ensuring adequate financing of family planning commodities and services

- Reducing early and unintended pregnancies among adolescents

- Improving family planning service delivery in humanitarian crises

- Ensuring contraceptive security through effective supply chains

- Expanding contraceptive choice

- Partnering with the private sector to strengthen provision of contraception

The authors alone are responsible for the views expressed in this article and they do not necessarily represent the views, decisions or policies of the institutions with which they are affiliated.

Family Planning Evidence Brief - Ensuring contraceptive security through effective supply chains: WHO/RHR/17.09

(c) World Health Organization 2017. Some rights reserved. This work is available under the CC BY-NC-SA 3.0 IGO license.

For more information, please contact: Department of Reproductive Health and Research, World Health Organization, Avenue Appia 20, $\mathrm{CH}-1211$ Geneva 27, Switzerland

E-mail: reproductivehealth@who.int

Website: www.who.int/reproductivehealth

Twitter: @HRPresearch

This material has been funded by UK aid from the UK government however, the views expressed do not necessarily reflect the UK government's policies.

Prepared July 2017 